\title{
A MÍDIA E O ÍDOLO RONALDO: ANALISANDO AS MATÉRIAS DA FOLHA ONLINE (2002-2009)'
}

\author{
MS. EVERTON DE ALBUQUERQUE CAVALCANTI \\ Secretaria Municipal da Educação, Prefeitura de Curitiba \\ (Curitiba - Paraná - Brasil) \\ E-mail: profevertoncavalcanti@hotmail.com
}

\author{
DR. ANDRÉ MENDES CAPRARO \\ Departamento de Educação Física, Universidade \\ Federal do Paraná (Curitiba - Paraná - Brasil) \\ E-mail: andrecapraro@onda.com.br
}

\begin{abstract}
RESUMO
A globalização tem levado a informação aos mais diversos locais, possibilitando a exposição da imagem dos ídolos esportivos por todo o planeta. O esporte tem sido considerado um exemplo para a formação de ídolos. Para tanto, faz-se necessário entender essa questão sociocultural: a relação interdependente do ídolo com a imprensa e o torcedor. O objetivo do presente estudo é de investigar como a imprensa retrata a imagem do ídolo Ronaldo "Fenômeno" e como isso se expressa no ideal do torcedor. A principal conclusão foi que a imprensa retrata a imagem do Ronaldo de acordo com os acontecimentos de sua vida pessoal e esportiva. Ou seja, quando a fase é positiva, o atleta é caracterizado como exemplo a ser seguido. Porém, quando a fase é negativa, é passível de críticas.
\end{abstract}

PALAVRAS CHAVE: Mídia; ídolo Ronaldo; folha online; futebol.

I. Agência de fomento: Reuni/UFPR (Reestruturação e expansão das Universidades Federais) Edital no 0 //20 I I. 
Líder do Brasil dos "erres" de Luiz Felipe Scolari, Ronaldo supera o trauma do fiasco de 1998, que terminou marcado por uma crise nervosa e pela derrota diante dos franceses na final. E entra para a história como unanimidade nacional, um craque completo, ídolo máximo do país do futebol (NAVARRO, 2002).

A Folha Online alça Ronaldo "Fenômeno" à condição de ídolo. Ao longo da história do esporte percebem-se possíveis influências do ídolo² no ideal do torcedor através da mídia. A globalização acelera o processo de difusão de informações pelos meios de comunicação, possibilitando uma maior exposição dos atletas, que passam a ser mais reconhecidos. Nas narrativas apresentadas pela mídia, o universo do esporte é considerado um exemplo para a produção do ídolo/herói - sua trajetória de vida sai do mundo cotidiano para transpor dificuldades, realizar feitos impossíveis e trazer conquistas ao seu povo (HELAL, 2003). O ídolo-herói se expressa por meio da cultura, procurando responder aos anseios de uma sociedade. São sujeitos dotados de talento, carisma e simpatia, o que os torna únicos e diferenciados. São poucos os jogadores que se tornam ídolos, destaques em seus clubes e que representam os seus respectivos selecionados (GIGLIO, 2007).

A trajetória de um ídolo é marcada por suas vitórias e conquistas. Porém, a derrota reconstrói o herói, ${ }^{3}$ proporciona-lhe enriquecimento, preparando-o para novos desafios e fazendo com que saia fortalecido para lutar por novas conquistas. Assim, o atleta/ídolo aprende a persistir diante da derrota e superar dificuldades, o que o torna uma referência para outros indivíduos (RÚBIO, 2006).

Mas o ídolo pode influenciar indivíduos de maneira positiva e negativa, pois suas atitudes podem ser interpretadas e absorvidas de acordo com o momento e a visão de cada torcedor. Sendo que a mídia mantém relação interdependente com os torcedores, elaborando as possíveis formas de transmissão das informações acerca dos ídolos. E tem-se um exemplo icônico...

Ronaldo Luiz Nazário de Lima, 35 anos completados no ano 201 I , nascido em 22 de setembro de 1976, no subúrbio de Bento Ribeiro, na cidade do Rio de Janeiro. Começou sua trajetória no futebol de campo, atuando pela equipe do São Cristóvão, da qual foi negociado com o Cruzeiro de Belo Horizonte. Em 1994 foi transferido para o PSV da Holanda e lá marcou 66 gols em 7I jogos. Em 1996

2. E neste sentido, o ídolo enquanto indivíduo portador de qualidades pessoais de força, vitalidade e auto-superação, fornece à sociedade um modelo digno de ser imitado (RIBEIRO, 2007).

3. "O herói enquanto figura mítica vem representar o mortal, que transcendendo essa sua condição aproxima-se dos deuses em razão de um grande feito" (RÚBIO, 200 I, p. 99). 
acabou se transferindo para o Barcelona da Espanha, marcando 48 gols em 51 jogos. Logo após foi contratado pela Internazionale de Milão em 1997. Em 2002, Ronaldo transferiu-se para o Real Madrid da Espanha, jogando até 2007, quando foi negociado com o Milan da Itália. Em dezembro de 2008, Ronaldo voltou ao Brasil, assinando contrato para jogar pelo Corinthians na temporada de 2009, na qual foi o artilheiro da equipe no ano, com 23 gols (RODRIGUES, 2009).

Não se pode dissociar do fenômeno esportivo os meios de comunicação e a organização social presente no espetáculo. Ao analisar o esporte, deve-se considerar que este é um fenômeno cultural de grande magnitude na sociedade atual, capaz de apresentar inúmeras situações e manifestações em relação aos diversos grupos sociais envolvidos (RÚBIO, 2002).

A metodologia aplicada no presente artigo segue os preceitos da História do Tempo Presente. Proposta que consiste em fazer uma história inacabada, na qual o historiador vive o tempo do seu próprio objeto. Logo, a compreensão facilitada pelo tempo em que se pesquisa permite a reconstrução da(s) forma(s) de sentir e pensar a história praticamente em tempo real (FERREIRA; FIGUEIREDO, 1998). O material empírico de análise (fontes históricas) foi constituído de um periódico de alcance nacional: a Folha Online - veículo de comunicação disponível na internet. O período delimitado na pesquisa vai de janeiro de 2002 a outubro de 2009, tendo em vista que nesse intervalo de tempo a carreira de Ronaldo teve seu auge, declínio e uma retomada ao sucesso.

Esta pesquisa tem por objetivo investigar como a imprensa brasileira - no caso, o periódico Folha Online - concebe a imagem do ídolo nacional Ronaldo "Fenômeno". Posteriormente, refletir sobre como repercute tal concepção na formação de um ideal que é incorporado pelos torcedores.

A hipótese central da pesquisa é a de que a imprensa retrata o ídolo de forma efêmera, ou seja, de acordo com os fatos do momento. Isso é repassado ao torcedor, que percebe os acontecimentos impulsivamente a partir da análise recente da mídia. Neste processo a condição consolidada de ídolo é substituída pela oscilação constante entre ser herói e ser vilão.

\section{TEORIZANDO: A REPRESENTAÇÃO DO ÍDOLO ESPORTIVO}

Algumas figuras - geralmente públicas - podem se tornar ídolos, consequentemente, são admirados. No meio esportivo - e especialmente no futebol - isso é comum por se tratar de um fenômeno cultural que abrange as expectativas de torcedores de diferentes sociedades e classes. Abordar-se-á o conceito de ídolo de maneira a relacioná-lo com outros conceitos próximos, como o de herói e vilão. De antemão, ressalta-se que os ídolos (ou os heróis) contribuem para a criação de ideais acerca do esporte (GIGLIO, 2007). 
A representação do ídolo pode provocar emoções, tal como o sentimento de amor e ódio. Estes indivíduos estão sujeitos a interpretações por parte da mídia e da população em geral, quase sempre superficiais e extremistas, pois são regularmente observados e julgados por suas atitudes e comportamentos em sua vida pública e privada (PILOTTO, 2000). O ídolo no futebol é aquele que cria raízes em determinada agremiação, conquistando o respeito da sociedade por meio do trabalho, dedicação, carisma e principalmente a conquista de títulos (GIGLIO, 2007).

É possível que através da imagem do ídolo os admiradores do futebol fortaleçam o sentimento de fascínio pelo esporte. O que permite pensar que há uma relação direta entre ídolo e torcedor, ou seja, para que o primeiro exista, é necessário que o segundo o idolatre (MORATO; GIGLIO; GOMES, 20 I I). Elaborando a ideia de que determinado jogador de futebol se estabelece como representante daqueles que o escolheram como ídolo. Esta relação pode ser considerada um dos possíveis motivos que permeiam o futebol pelo campo da paixão (RIBEIRO, 2004; PILOTTO, 2000).

O conceito de ídolo se confunde por vezes com o do herói. Sabe-se que o herói é aquele que realiza um feito de determinada importância, como um gol decisivo na conquista de um título. Kátia Rúbio define tal conceito da seguinte forma:

Se enquanto figura arquetípica o herói vem representar o mortal que transcendendo essa sua condição aproxima-se dos deuses em razão de um grande feito, nos dias atuais temos no atleta de alto rendimento uma espécie de herói capaz de protagonizar a realização de grandes feitos cada vez mais raros em outros settings (RÚBIO, 2007, p. 665).

A autora acima citada afirma que durante determinado período o herói gera uma admiração social devido a uma realização, que proporciona a manutenção do seu status por um determinado período e é registrado na história. De certa forma, ambos, tanto ídolo como o herói, têm suas vidas modificadas pelo sucesso de seus feitos. Independentemente da proporção da mudança, o fato é que se tornaram pessoas públicas e levam consigo a responsabilidade de representar uma população com expectativa de mais vitórias (GIGLIO, 2007).

O herói aparece como o indivíduo que se divide em dois sujeitos, numa espécie de duplicidade (KOTHE, 1985). No caso de Ronaldo, o ser humano Ronaldo Nazário de Lima e o jogador Ronaldo "fenômeno". O primeiro é passível de vitórias e fracassos, problemas e dificuldades que a vida cotidiana impõe, já o segundo é considerado o indivíduo capaz de superar qualquer obstáculo, apontado por quem Ihe condiciona como herói, como o sujeito capaz de realizar feitos improváveis no futebol, sendo decisivo em uma vitória ou conquista.

O herói se caracteriza por realizar um feito histórico, às vezes único, desenvolvido em um curto espaço de tempo, como um gol importante na conquista 
de um título. Por sua vez, o ídolo é o sujeito que constrói sua condição ao longo do tempo, conforme seu desempenho a médio e longo prazo, como a conquista de vários títulos representando um mesmo clube. (GIGLIO, 2007). Por exemplo, pode-se citar o atleta Adriano "Gabiru":

Ídolo da torcida do Atlético-PR e herói do Internacional [...]. Gabiru foi campeão brasileiro pelo Atlético-PR, em 200 I , mas teve seu momento de consagração, ao marcar o gol que deu o título do Mundial Interclubes ao Internacional, na final com o Barcelona, em 2006 (HERÓı, 20 I 0).

Em contrapartida ao conceito de herói, tem-se o de vilão. Os vilões são os indivíduos responsabilizados por algum fracasso em momento decisivo (RINALDI, 2000). O meio esportivo está relacionado ao sentido de competição, logo, os atletas devem conviver com o sucesso e o fracasso. Ambiente no qual a vitória de um acaba por definir a derrota de seu adversário, determinando heróis e vilões nas disputas (COSTA, 2007). Assim, pode-se citar um exemplo recente, o do jogador Felipe Melo na Copa do Mundo de 20 I0. O portal globoesporte.com, na manchete do dia após o jogo contra Holanda, estampava: "Felipe Melo passa de herói a vilão na eliminação brasileira na Copa - Após ótimo lançamento para gol do Brasil, volante que foi aposta de Dunga faz gol contra e recebe cartão vermelho no segundo tempo" (FELIPE, 20I0).

Outro exemplo é o do jogador Roberto Carlos, considerado pela mídia e pelo público em geral como o culpado pela eliminação do Brasil na Copa do Mundo de 2006. Como retratado no trecho a seguir:

Antes do fiasco na Alemanha, Roberto Carlos havia dito que pretendia continuar defendendo a seleção. Seu desempenho pífio no torneio, porém, o fez mudar de idéia. Criticado por torcedores em todas as partidas do Mundial, o jogador ainda ficou com a pecha de vilão no lance do gol da França, marcado por Henry. Em vez de marcar o atacante francês, Roberto Carlos se abaixa na hora da cobrança de Zidane, enquanto Henry invade a área sozinho e faz o gol que selaria a eliminação brasileira (ROBERTO CARLOS, 2006).

Também conhecido como anti-herói, o vilão esportivo está associado à imagem do atleta em toda a sua complexidade: dentro de campo, como explicado anteriormente, podendo atingir também a vida privada, ou seja, é complicado separar o profissional do pessoal. É o caso de jogadores que por vezes se envolvem em episódios repudiados pela sociedade e que, de certa forma, são explorados pelo jornalismo esportivo (CIACARELI; GAWRYSZENSKI, 2009). Os casos polêmicos envolvendo os jogadores do Flamengo nos últimos anos são bons exemplos: “Adriano, Vagner Love e Bruno: Fla vira 'caso de polícia' em 2010 - Investigado no 
desaparecimento da estudante Eliza Samudio, goleiro amplia lista que já teve Love e Adriano acusados de envolvimento com traficantes".

A mídia é uma das responsáveis por este processo de popularização da imagem de um ídolo no esporte. Esta, que possui papel importante no processo de formação do ídolo esportivo, será tratada a seguir.

\section{MÍDIA E FUTEBOL}

futebol é a modalidade esportiva mais importante no Brasil, tanto que é considerado um dos principais elementos da cultura nacional (SOARES; HELAL; SANTORO, 2004). Com esse grau de importância, evidentemente, o futebol sofre grande influência da mídia em geral, tendo uma enorme cobertura por parte da imprensa.

A mídia ${ }^{4}$ exerce papel importante na criação e divulgação do ídolo. Com a intensificação da globalização, a presença dessa figura acontece de forma constante no futebol (MARQUES, 2005). Antigamente, apenas o rádio e os jornais existiam como canais entre o público e o espetáculo, porém, com o passar dos anos, a televisão e a internet facilitaram o acesso aos eventos esportivos (GIGLIO, 2007).

Os atletas que carregam a alcunha de ídolo, muitas vezes exercem um papel de exemplo para os indivíduos apreciadores do esporte. E o modo como a imprensa trata tal agente pode comprometer a maneira como este se comporta socialmente. Dada a sua importância, o ídolo pode influenciar na definição dos papéis sociais, colaborando de certa maneira na forma de agir e pensar da população em geral (PILOTTO, 2000). Rúbio esclarece:

\footnotetext{
atleta profissional do esporte contemporâneo tem sido, graças ao poder e influência que os meios de comunicação de massa têm sobre o espetáculo esportivo, tratado e reconhecido como personalidade pública, ídolo, herói e ideal de ego de grande parte da juventude e dos adultos, porque à sua figura estão associados o sucesso, a fama e uma vida vitoriosa, valores cultivados e desejados pela sociedade atual (RÚBIO, 2002, p. I).
}

A mídia acompanha a vida dos ídolos. Seu sucesso, suas vitórias e títulos são transmitidos ao torcedor como se estes espectadores participassem ativamente deste campo, fazendo, então, parte das conquistas daqueles que consideram como exemplo a ser seguido. Pode-se usar a seleção nacional como exemplo, pois a mídia relaciona a imagem dos jogadores a um grupo vencedor, fazendo com que o torcedor se sinta parte integrante deste contexto vitorioso, mesmo que esta relação

4. Mídia pode ser entendida como: $O$ conjunto de instituições que utiliza tecnologias específicas para realizar a comunicação humana (GUAZINA, 2007). 
se contradiga no cotidiano desses sujeitos (SOARES; HELAL; SANTORO, 2004). A veiculação do ídolo esportivo pela mídia faz parte de uma recriação artística/tecnológica, servindo como exemplo de superação a determinados insucessos da vida cotidiana, afirmando intrinsecamente o desejo de ascensão social dos indivíduos de uma dada sociedade (GIGLIO, 2007).

No processo de divulgação dos ídolos pela mídia, não se edificam apenas sujeitos de sucesso, criam-se eras que vão determinar o período de apogeu e declínio. Além de tratar do auge, esta relação trata da queda destes sujeitos. Na criação da imagem de um ídolo não é apenas o desempenho que influencia, mas a vida pessoal, sua intimidade, seus bens, tudo que pode ser associado como elemento constituinte é levado em consideração pelos meios de comunicação (PILOTTO, 2000). Como retratado pela Folha Online no episódio em que Ronaldo foi acusado de envolvimento com três travestis em um motel na Barra da Tijuca:

O atacante Ronaldo do Milan foi parar numa delegacia na madrugada de segunda-feira, após se envolver em confusão com três travestis. Ele e um dos travestis foram encaminhados à delegacia pela Polícia Militar, depois de uma discussão em um motel. (EM NOTA, 2008).

Mídia, ídolo e espectador se relacionam em um processo interdependente. $\bigcirc$ ídolo necessita de identificação com o torcedor para que sua imagem seja propagada pelos meios de comunicação, os quais precisam dos ídolos para atrair espectadores, e dos mesmos para ter retorno acerca do desempenho dos jogadores. Por último, ao torcedor cabe a escolha dos seus ídolos, identificação a qual permite elaborar o que a mídia pode reproduzir nos meios de comunicação.

\section{O ÍDOLO NA MÍDIA: RONALDO "FENÔMENO" NA FOLHA ONLINE}

A Folha Online é o site do jornal Folha de São Paulo, veículo de comunicação que transmite notícias dos mais variados assuntos. Far-se-á a seguir uma relação de como este importante veículo de comunicação cria uma imagem estereotipada acerca do ídolo Ronaldo "Fenômeno".

Ronaldo é considerado pela imprensa como um símbolo do futebol nacional, podendo ser enquadrado nas categorias de ídolo e (por vezes) de herói (ADAMI; HELLER, CARDOSO, 2003). Pois, o herói é aquele que corre perigos, consegue realizar feitos históricos e transpor desafios quase inalcançáveis, sempre de forma rápida e contundente, fazendo com que o público enaltecesse seu feito pelo valor histórico (GIGLIO, 2007; KOTHE, 1985). Após a Copa do Mundo de 2002, Ronaldo é elevado ao patamar de herói do título mundial por ter sido decisivo em todos os jogos da seleção, também retratado como ídolo nacional, já que sua longa carreira na seleção brasileira o consagrou com o maior título que um jogador de 
futebol poderia conquistar. O periódico Folha Online chega a comparar o atleta a Pelé, considerado o maior jogador de todos os tempos.

Saiu dos pés dele, duas vezes, dos pés mágicos dele. Foram os gols do título, do pentacampeonato, da redenção. Gols de Ronaldo, do "Fenômeno", que elevaram o Brasil à condição de máxima potência do futebol depois de oito anos [...] Prevaleceu a genialidade do astro, que hoje traz a Copa nos braços e entra para a memória do futebol igualando-se a Pelé, ambos com 12 gols em Mundiais [...] (NAVARRO, 2002).

Essa formulação que é transmitida pela mídia é incorporada à imagem que o torcedor tem do seu ídolo. Assim, a veiculação positiva de determinada notícia acaba por fortalecer o atleta como ídolo, já que este proporcionou a alegria de uma conquista importante. A Folha Online relata uma pesquisa na qual Ronaldo é eleito pelos torcedores paulistanos o melhor jogador da seleção brasileira na Copa de 2002. Recebeu média de 9,7 sendo que $81 \%$ dos entrevistados lhe atribuíram nota máxima (MAIORIA, 2002)

Apesar de ser considerada uma figura singular do esporte nacional, Ronaldo também sofreu com a velocidade em que o apogeu/declínio de sua imagem se estabeleceu. $\bigcirc$ torcedor brasileiro antes de tudo é considerado bastante passional e a mídia intensifica tais sentimentos, tanto pelo lado positivo, quanto pelo negativo, dependendo de como os fatos se apresentem a ela (a mídia). Sendo assim, se Ronaldo cumpre seu papel com sucesso é um "Fenômeno", senão, é um jogador possível de ser criticado, quem sabe, em algumas circunstâncias, até um vilão (GONÇALVES, 2009).

$\mathrm{Na}$ Folha Online de $1^{\circ}$ de julho de 2006, Ronaldo é criticado por nunca ter conseguido marcar gols em jogo de quartas-de-final de Copa do Mundo, o que em 2006 colaborou para o fracasso da seleção brasileira diante da França (NERY, 2006). Em outro caso de crítica da imagem do ídolo, A Folha Online reproduz uma reportagem do tablóide inglês The Sun no qual Ronaldo é ridicularizado. Chamado de gordo, o periódico sensacionalista inglês destacava que o jogador teve sua carreira arruinada por sua (falta de) forma física (JORNAL, 2008).

Destaque para a questão da efemeridade no tratamento dos fatos, pois quando Ronaldo foi artilheiro do Mundial e considerado melhor jogador do mundo em 2002, as notícias tratavam de enaltecer seus feitos, fazendo menção a sua condição de superador de obstáculos. Porém, quando a fase não era favorável (como em 2006), as críticas se estabeleceram sem nenhuma referência ao que o jogador realizou e representou no passado próximo. Demonstrando também a transição da condição de herói e vilão em curto espaço de tempo, justamente pela importância dada aos fatos abordados pela mídia, os quais são destaques por um determinado momento, sendo esquecidos depois que deixam de ser inéditos. 
Observa-se nesse processo o apogeu e o declínio do ídolo, de acordo com a definição daquilo que é definido socialmente como "comportamento regrado". No presente caso, após passar por um período de quase um ano sem jogar futebol e ter destaque negativo na mídia devido à sua forma física e vida pessoal, o ídolo Ronaldo acerta seu retorno ao futebol brasileiro para jogar pelo Corinthians.

A Folha Online de 09 de dezembro de 2008 (CORINTHIANS, 2008) coloca como manchete a seguinte frase: "Corinthians acerta com o astro Ronaldo para a temporada 2009". Em notícia publicada um dia antes, A Folha Online tratou de Ronaldo como um astro internacional, mencionando que a torcida corintiana estava preparando uma grande festa para recepcionar seu novo ídolo (GURGEL, 2009). Isso mostra a dimensão social/midiática da imagem do jogador que, mesmo antes de jogar pelo novo clube, já é alçado à condição de ídolo. Kátia Rúbio (2002) afirma que a expectativa gerada pela prática do esporte influencia o padrão de comportamento daqueles que optaram pelo esporte como profissão. $\bigcirc$ desenvolvimento de práticas coletivas e comportamentos individuais propiciam o que comumente é chamado de cultura esportiva, aquilo que procede a criação e multiplicação do ideal esportivo, delineador das "biografias" dos atletas que ainda estão em atividade.

Gurgel (2009) retrata que, por Ronaldo ser considerado um dos maiores jogadores da história do futebol brasileiro e maior artilheiro de todas as Copas do Mundo, é natural a cobertura exagerada pelos meios de comunicação. A Folha Online de 05 de março estampa a repercussão da volta de Ronaldo ao futebol brasileiro. $\bigcirc$ texto relata que antes da partida, o atleta foi cercado pelos jornalistas enquanto fazia o aquecimento e também depois, quando se deslocava para o banco de reservas. Após o jogo houve tumulto entre os repórteres que queriam entrevistar o atleta. No dia seguinte à volta aos gramados, a repercussão foi em todo o mundo, com destaque para os jornais La Gazzetta dello Sport (Itália), Marca (Espanha) e Guardian (Inglaterra) (VEJA, 2009) A imagem de Ronaldo se adequa ao papel de ídolo e/ou herói estabelecido pela mídia, já que sua trajetória pessoal favorece a criação de uma narrativa de superação de dificuldades e desafios. A Folha Online pode servir de exemplo, ao exibir o seguinte título: "Ronaldo ressurge de novo e, aos 32, volta a vencer no Brasil". No texto, o jornal acentua a trajetória do jogador na equipe brasileira, enfatiza as inúmeras vezes em que o atleta foi desacreditado em relação ao futebol e o enaltece chamando-o novamente de "Fenômeno", 5 comentando seu poder de decisão na fase final do campeonato paulista (RONALDO, 2009).

Outra característica típica do apogeu/declínio da imagem icônica do atleta é o acentuar da fidelização. $\bigcirc$ reconhecimento do esforço corporal torna-se alvo da

5. Para Cavalier, fenômeno significa aquele que se mostra ou se manifesta. (CAVALIER, R. Disponível em: < http:// caae.phil.cmu.edu/Cavalier/80254/Heidegger/introductions/Phenomen.html> Acesso em: 26 jun. 20 I0). 
mídia de diferentes maneiras: informando e alimentando o estereótipo, instigando o desejo de ser determinado atleta, obter seus resultados, ter sua capacidade, seu corpo, interpretando o mundo de forma paralela a sua realidade (SEBRENSKI; CAPRARO; CAVICHIOLLI, 20I0). Mesmo que o futebol-espetáculo (PRONI, 2000) apresente uma grande circularidade de atletas de acordo com o mercado consumidor, não permitindo a criação de vínculos mais sólidos e duradouros, ${ }^{6}$ a presença em um clube, mesmo que efêmera, é permeada por uma "paixão arrebatadora". A Folha Online de 20 de outubro apresentou a seguinte manchete: "Ronaldo diz que fica no Corinthians e fala em "parceria eterna'”. No texto o jornal reforçava que Ronaldo estava próximo de renovar o contrato com o clube, pois o considerava um "eterno parceiro". O atleta concluiu a entrevista dizendo: "Sou corintiano e vou encerrar minha carreira aqui" (RONALDO, 2009a). Tal afirmativa fez com que boa parte da torcida corintiana o elevasse ainda mais à condição de ídolo. É mais uma mostra que o futebol pertence ao campo da paixão (RIBEIRO, 2004).

\section{CONSIDERAÇÕES FINAIS}

A pesquisa, centrada na análise de um periódico em específico, permitiu o delineamento de alguns parâmetros para ampliar a discussão acerca da exibição da imagem do atleta na mídia.

Observou-se em primeira instância que o esporte, e especificamente o futebol, é um meio propício para a criação dos ídolos. A imagem do ídolo acontece de acordo com as características apresentadas pelo indivíduo. Para se tornar um ídolo é necessário, por exemplo, demonstrar: carisma, engajamento no trabalho, seriedade (conduta moral socialmente aguardada) e conquistas pessoais e esportivas. Alguns acabam confundindo os conceitos de ídolo e herói. A diferença consiste na questão temporal. $O$ ídolo realiza feitos a médio e longo prazo, adquirindo capital simbólico (BOURDIEU, 2002) como na conquista de vários títulos por um mesmo clube; já o herói conquista sua condição através de um feito em curto prazo, como na realização de um gol em uma partida decisiva (GIGLIO, 2007).

No caso de Ronaldo, é notório seu pouco tempo de clube e seu currículo curto de conquistas pelo Corinthians; porém, ele traz consigo uma imagem de vencedor por onde passou, em especial pela seleção brasileira, o que o eleva à condição de ídolo de um clube brasileiro mesmo antes de ter entrado em campo. Isso tudo, somado ao primeiro semestre bem sucedido com a conquista de dois

6. Nas décadas passadas era característica dos atletas a identificação com um clube em especial, como nos casos de Pelé/Santos, Zico/Flamengo, Sócrates/Corinthians, Roberto Dinamite/Nasco e Ademir da Guia/Palmeiras. 
títulos (Copa do Brasil e Campeonato Paulista), além dos gols decisivos marcados contra São Paulo, Santos e Internacional, aceleraram o processo de identificação de Ronaldo como ídolo do Corinthians.

Os feitos de um ídolo provocam reações na imprensa e no público que o acompanha. A imprensa, de acordo com interesses diversos, retrata segmentos do cotidiano que, por sua vez, provocam algum tipo de reação nos torcedores, o que, por outro lado, também influencia o que a mídia transmite acerca dos ídolos (RÚBIO, 2002).

Os veículos de comunicação são a ligação entre o ídolo e o torcedor, portanto, possíveis potencializadores da criação de ideais e estereótipos (VIEIRA, 2007). E como processual ele é um dos responsáveis pela divulgação do apogeu e do declínio da imagem do ídolo, de forma a responsabilizá-lo pelo sucesso em caso de vitória e pelo fracasso em caso de derrota sucessivamente, ou seja, reduzi-lo de forma efêmera, já que rapidamente o transforma ora em herói, ora em vilão.

Em relação ao atacante Ronaldo, observou-se que este é alvo de variados meios de comunicação. No caso do periódico analisado, a Folha Online, é observável a difusão de uma imagem que remete a ideia de superação. E, para que exista a redenção, é necessária a crise. Observa-se, então, que a imprensa retrata a imagem do jogador Ronaldo de acordo com os acontecimentos da sua vida esportiva e pessoal. Quando em boa fase é elevado à condição de exemplo a ser seguido. Quando não corresponde às expectativas é passível de críticas ácidas em relação a seu desempenho, reforçando ainda mais a ideia de efemeridade em relação aos fatos ocorridos.

\section{Media and the Idol Ronaldo: Analyzing Articles of Folha Online (2002-2009)}

ABSTRACT: Globalization has brought the information to several sites, enabling the display of the image of sports heroes around the globe. Sport has been considered fertile ground for the formation of idols. Therefore, it is necessary to understand the sociocultural issue: the interdependent relationship of the idol with the press and fans. The aim of this study is to investigate how the media portrays the image of the idol Ronaldo and how it expresses itself in the ideal of the fans. The main conclusion was that the media portrays the image of Ronaldo in accordance with the events of his personal life and sports. Namely, when the phase is positive, the athlete is featured as an example to be followed. However, when the phase is negative, it is open to criticism.

KEYWORDS: The media; Ronaldo idol; folha online; soccer. 


\section{Los medios de comunicación y el idolo Ronaldo: análisis de los artículos de la folha online (2002-2009)}

RESUMEN: La globalización ha traído consigo la información de varios sitios, lo que permite la visualización de la imagen de los héroes deportivos de todo el mundo. El deporte ha sido considerado como un terreno fértil para la formación de los ídolos. Por lo tanto, es necesario entender la cuestión socio-cultural: la relación de interdependencia del ídolo con la prensa y los fans. El objetivo de este estudio es investigar cómo los medios representan la imagen del ídolo de Ronaldo y la forma en que se expresa en el ideal de los aficionados. La conclusión principal fue que los medios retratan la imagen de Ronaldo de conformidad con los acontecimientos de su vida personal y deportiva. Es decir, cuando la fase es positiva, el atleta se presenta como un ejemplo a seguir. Sin embargo, cuando la fase es negativa, está abierto a la crítica. PALABRAS CLAVE: Los medios de comunicación; Ronaldo idol; folha online; fútbol.

\section{REFERÊNCIAS}

ADAMI, A.; HELLER, B.; CARDOSO, H. D. F. Mídia, cultura e comunicação. São Paulo: Arte e Ciência, 2003.

ADRIANO, WAGNER LOVE E BRUNO: FLA VIRA 'CASO DE POLÍCIA' EM 20I0. Globoesporte.com, Rio de Janeiro, 27 jun. 20 I0. Disponível em: <http://globoesporte.globo. com/futebol/times/flamengo/noticia/20 I 0/06/adriano-vagner-love-e-bruno-fla-vira-caso-depolicia-em-20l0.html> Acesso em: 12 nov. 2010.

BOURDIEU, P. O poder simbólico. 5. ed. Rio de Janeiro: Bertrand Brasil, 2002.

CAVALIER, R. Syllabus, 27 mar. 2008. Disponível em: <http://caae.phil.cmu.edu/Cavalier/80254/Heidegger/introductions/Phenomen.htm>. Acesso em: 26 jun. 2010.

CIACARELI, N.; GAWRYSZEWSKI, A. A representação imaginética das festividades e dos "heróis" na imprensa anarquista ( 190 I - 1927). In: ENCONTRO NACIONAL DE ESUDOS DA IMAGEM, 2., 2009, Londrina. Anais ... Londrina: UEL, 2009. p. 195-206.

CORINTHIANS ACERTA COM O ASTRO RONALDO PARAA TEMPORADA 2009. Folha de São Paulo, São Paulo, 9 dez. 2008. Disponível em: <http://wwwl folha.uol.com.br/folha/ esporte/ult92u477057.shtml>. Acesso em: 25 maio 2010.

COSTA, M. L. Os vilões da derrota da seleção brasileira. A importância do resultado nas narrativas jornalísticas sobre futebol. In: ENCONTRO DA ASSOCIAÇÃO NACIONAL DE HISTÓRIA , 13., 2007, Rio de Janeiro. Anais ... Rio de Janeiro: ANPUH, 2007. p. I-8.

EM NOTA, RONALDO NEGA CHANCE DE IRA DELEGACIA DEPOR SOBRE TRAVESTIS. Folha de São Paulo, São Paulo, 29 abr. 2008. Disponível em: < http://wwwl folha.uol.com. br/folha/esporte/ult92u39686I .shtml>. Acesso em: 22 maio 2010. 
FELIPE MELO PASSA DE HERÓI A VILÃO NA ELIMINAÇÃO BRASILEIRA NA COPA. Globoesporte.com, Rio de Janeiro, 2 jul. 20 I 0. Disponível em: < http://globoesporte.globo. com/futebol/selecao-brasileira/noticia/20 10/07/felipe-melo-vai-de-heroi-vilao-na-eliminacaobrasileira.html>. Acesso em: 27 nov. 2010.

FERREIRA, M. M.; FIGUEIREDO, J. P. A. B. Uso e abusos da história oral. Rio de Janeiro: Fundação Getúlio Vargas, 1998.

GIGLIO, S. Futebol: mitos, ídolos e heróis. 2007. I 62 f. Dissertação (Mestrado em Educação Física) - Faculdade de Educação Física, Universidade Estadual de Campinas, Campinas, 2007.

GONÇALVES, G. A. Ronaldo, herói ou vilão? Disponível em: < http://profguillermo.50webs. com/Arquivos/artigos/periodicos/Ronaldo_heroi_ou_vilao.pdf> Acesso em: 29 out. 2009.

GUAZINA, L. O conceito de mídia na comunicação e na ciência política: desafios interdisciplinares. Revista Debates, Porto Alegre, v. I, n. I, p. 49-64, jul./dez. 2007.

GURGEL, A. Ronaldo em dois tempos no jogo econômico. In: CONGRESSO BRASILEIRO DE CIÊNCIAS DA COMPUTAÇÃO, 32., 2009, Curitiba. Anais... Curitiba, INTERCOM, 2009. p. $|-| 5$.

HELAL, R. A construção de narrativas de idolatria no futebol brasileiro. Alceu, Rio de Janeiro, v. 4, n. 7, p. 19-36, jul./dez. 2003.

HERÓI DO INTERNACIONAL, GABIRU TENTA RETOMAR CARREIRA NO CORINTHIANS-PR. UOL, Rio de Janeiro, 21 de out. 20l0. Disponível em: < http://esporte.uol. com.br/futebol/ultimas-noticias/20 I 0/I 0/2 I/heroi-do-titulo-do-inter-adriano-gabiru-vai-jogarno-corinthians-pr.jhtm>. Acesso em: 15 nov. 2011 .

JORNAL INGLÊS MOSTRA RONALDO GORDO, DE CUECA E FUMANDO. Folha de São Paulo, São Paulo, jul. 2008. Disponível em: <http://wwwl .folha.uol.com.br/folha/ilustrada/ ult90u4 | 8452. shtml>. Acesso em: 22 maio 2010.

KOTHE, F. R. O herói. São Paulo: Ática, 1985.

MAIORIA DA NOTA MÁXIMA A RONALDO. Folha de São Paulo, São Paulo, 2 jul. 2002. Disponível em: < http://www I folha.uol.com.br/folha/esporte/ult92u44 I I3.shtml > . Acesso em: 12 maio 2010.

MARQUES, J. C. O mito construído, destruído e restituído: o caso cíclico de Ronaldo fenômeno. In: CONGRESSO BRASILEIRO DE CIÊNCIAS DA COMUNICAÇÃO, 28., 2005, Rio de Janeiro. Anais ... Rio de Janeiro: INTERCOM, 2005. p. I- 16.

MORATO, M. P.; GIGLIO, S. S.; GOMES, M. S. P. A construção do ídolo no fenômeno futebol. Motriz, Rio Claro, v. 17, n. I, p. I-10, jan./mar. 201 I.

NAVARRO, S. Ronaldo iguala Pelé e traz o pentacampeonato. Folha de São Paulo, São Paulo, 30 jun. 2002. Disponível em: <http://wwwl folha.uol.com.br/folha/esporte/ult92u43977. shtml>. Acesso em: 10 jun. 2010. 
NERY, A. L. Ronaldo mantém seca de gols em quartas-de-final de Copa. Folha de São Paulo, São Paulo, I jul. 2006. Disponível em: <http://wwwl.folha.uol.com.br/folha/esporte/ ult92ul05076.shtml> Acesso em: 21 maio 2010.

PILOTTO, F. M. A Fabricação dos ídolos esportivos. In: REUNIÃO ANUAL DAASSOCIAÇÃO NACIONAL DE PÓS-GRADUAÇÃO E PESQUISA EM EDUCAÇÃO, 23., 2000, Caxambu. Anais... Caxambú: ANPEd, 2000. p. I-17.

PRONI, M. A metamorfose do futebol. Campinas: Ed. Da Unicamp, 2000.

RIBEIRO, L. A. S. A emergência dos heróis do futebol no contexto da sociedade actual. 2007. 99 f. Trabalho de Conclusão de Curso (Licenciatura em Desporto e Educação Física) - Faculdade de Desporto, Universidade do Porto, Porto, 2007.

RIBEIRO, L. C. O futebol no campo afetivo da história. Movimento, Porto Alegre, v. I0, n. 3, p. 99-। I I, set./dez. 2004.

RINALDI, W. Futebol: manifestação cultural e ideologização. Revista da Educação Física/UEM, Maringá, v. I I n. I, p. 167-172, 2000.

RODRIGUES, R. Ronaldo ficou a sete gols de sua meta para 2009. Futebol em Números, 3 dez. 2009. Disponível em: <http://colunistas.ig.com.br/futebolemnumeros/2009/12/03/ ronaldo-ficou-a-7-gols-de-sua-meta-para-2009/>. Acesso em: 25 out. 2010.

ROBERTO CARLOS ANUNCIA APOSENTADORIA DA SELEÇÃO BRASILEIRA. Folha de São Paulo, São Paulo, 03 jul. 2006. Disponível em: <http://wwwl folha.uol.com.br/folha/ esporte/ult92ul05240.shtml>. Acesso em: 23 set. 2010.

RONALDO DIZ QUE FICA NO CORINTHIANS EM 2010 E FALA EM "PARCERIA ETERNA”. Folha de São Paulo, São Paulo, 20 out. 2009. Disponível em: < http://wwwl .folha.uol. com.br/folha/esporte/ult92u6405 I 5.shtml>. Acesso em: 27 set. 2010.

RONALDO RESSURGE DE NOVO E, AOS 32, VOLTA A VENCER NO BRASIL. Folha de São Paulo, São Paulo, 3 maio 2009. Disponível em: <http://wwwl lfolha.uol.com.br/folha/ esporte/ult92u5596 19.shtml>. Acesso em: 20 jun. 2010.

RÚBIO, K. O atleta e o mito do herói: o imaginário esportivo contemporâneo. São Paulo: Casa do Psicólogo, 2001.

RÚBIO, K. O imaginário da derrota no esporte contemporâneo. Psicologia e Sociedade, Florianópolis, v. 18, n. I, p. 86-91, jan./abr. 2006.

RÚBIO, K. O trabalho do atleta e a produção do espetáculo esportivo. Revista Eletrônica de Geografia y Ciências Sociales, Barcelona, v. 6, n. I19, ago. 2002.

RÚBIO, K. Do imaginário esportivo ao mito olímpico contemporâneo. In: MORAGAS, M.; DA COSTA, L. P. (Org.). Universidad y estudios olímpicos. Bellaterra: Universitat Autonoma de Barcelona, 2007. v. I. p. 660-676. 
SOARES, A. J.; HELAL, R.; SANTORO, M. A. Futebol, imprensa e memória. Revista FronteirasEstudos Midiáticos, São Paulo, v. 6, n. I, p. 6I-78, 2004.

SEBRENSKI, R. M.; CAPRARO, A. M.; CAVICHIOLLI, F. R. Estética no esporte: notas iconográficas sobre duas "estrelas" - Anna Kournikova e David Beckham. Pensar a Prática, Goiânia, v. 13, n. I, p. I-17, jan./abr. 2010.

VEJA REPERCUSSÃO SOBRE A VOLTA DE RONALDO NA IMPRENSA INTERNACIONAL. São Paulo, 05 mar. 2009. Disponível em: <http://wwwl.folha.uol.com.br/folha/esporte/ ult92u5298 17.shtml>. Acesso em: I I jun. 2010.

VIEIRA, M. V. Mito e herói na contemporaneidade: as histórias em quadrinhos como instrumento de crítica social. Contemporânea, Bahia, n. 8, p. 78-90, 2007.

Recebido em: | 4 abr. 20 I I Aprovado em: 01 out. 2011

Endereço para correspondência: Everton de Albuquerque Cavalcanti Rua. Mário Chaulbald Biscaia, 225, apto. 13 Bairro Novo Mundo Curitiba - PR CEP: $81050-240$ 